\title{
Distinguishing Coconut Oil from Coconut Paring Oil using Principle Component Analysis of Fatty Acid Data
}

\author{
J.M.N. Marikkar* and A.R. Nasyrah
}

\begin{abstract}
A study was carried out to distinguish coconut oil from coconut pairing oil by the application of principal component analysis (PCA) to fatty acid compositional and iodine value data. Five samples of ordinary coconut oil extracted from five different batches of copra and five samples of coconut pairing oil obtained from five batches of dried coconut pairings were employed. Fatty acid composition and iodine values of oil samples were determined individually and the data were analyzed statistically. PCA analysis showed that lauric and oleic acid contents and iodine value data are the most influencing parameters to discriminate coconut oil from coconut pairing oil. Hence, the application of PCA to fatty acid compositional and iodine value data was successful in distinguishing coconut oil from coconut pairing oil.
\end{abstract}

Keywords: Authentication, coconut oil, coconut pairing oil, fatty acid, iodine value, PCA

*Halal Products Research Institute, Universiti Putra Malaysia, 43400 UPM Serdang, Selangor D.E., Malaysia. Email: nazrim_marikkar@putra.upm.edu.my 


\section{Introduction}

The brownish outer covering of coconut kernel serving as a protective layer is traditionally known as coconut paring. Owing to its dark brown color, paring is usually removed before the processing of the kernel into products such as desiccated coconut, coconut cream and milk powder. In the industrial processing of coconut, the coconut paring is removed by manually operated paring knives and it is reported that approximately $18 \% \quad(\mathrm{w} / \mathrm{w}$, wet basis) of the total kernel weight is lost due to the removal of paring (Marikkar and Madhrapperume, 2011). In fact, paring is the part of the coconut kernel where oil is more concentrated (Nathanael, 1966), and hence, it is used as a by-product to extract oil which is traditionally known as coconut paring oil. Normal coconut oil usually differs from coconut paring oil due to slight difference in fatty acid composition and iodine value. Other than this, moisture and free fatty acid contents of coconut paring oil are also generally found to be higher than the acceptable limits due to shortcomings in the processing method of coconut parings. Particularly, a delay in the drying of coconut paring could urge microbial invasion leading to the quality deterioration of coconut parings. As a result, the oil that is extracted from the parings could be inferior in terms of various quality attributes. Owing to this situation, oil traders usually under value coconut paring oil as industrial grade oil, which gets a lower premium in the market place. The price difference between coconut pairing oil and normal coconut oil has frequently lead to adulteration practices in the coconut oil trade. This kind of practice not only misleads the consumers by falsifying information, but also it denies their right to get genuine product for the price they pay. Hence, it is important to establish analytical methodology which can distinguish normal coconut oil from coconut pairing oil. In this study, the application of chemometric techniques such as PCA to fatty acid composition and iodine value data has been investigated for distinguishing coconut oil from coconut pairing oils.

\section{Materials and Methods}

\section{Materials:}

Five different coconut oil (CNO) samples identified by their sample codes (CNO-1, CNO2, CNO-3, CNO-4, and CNO-5) were obtained in replicates from processing of five different batches of copra using screw press oil expeller (Udaya Expeller, Udaya Industries of Sri Lanka). Similarly, five different coconut paring oil (CPO) samples identified by their sample codes (CPO-1, CPO-2, CPO-3, CPO-4, and CPO-5) were obtained in replicates from processing of five different batches of coconut paring samples using the same oil expeller.

\section{GLC analysis of fatty acid methyl esters (FAME):}

FAME were prepared by dissolving $50 \mathrm{mg}$ portion of oil in $0.8 \mathrm{ml}$ of hexane and adding 0.2 $\mathrm{ml}$ portion of $1 \mathrm{M}$ solution of sodium methoxide (PORIM, 1995) and analyzed on a gas chromatograph (Agillent Technologies, Singapore) fitted with a FID detector. The polar capillary column RTX-5 $(0.32 \mathrm{~mm}$ internal diameter, $30 \mathrm{~m}$ length and $0.25 \mu \mathrm{m}$ film thickness; Restex Corp., Bellefonte, PA) was used. The oven temperature was programmed as follows: initial temperature of $50^{\circ} \mathrm{C}$ (for $1 \mathrm{~min}$ ), and programmed to increase to $200^{\circ} \mathrm{C}$ at $8^{\circ} \mathrm{C} / \mathrm{min}$. Both injector and detector temperatures were maintained at $200^{\circ} \mathrm{C}$ throughout the analysis. The carrier gas (helium) flow rate was $1.0 \mathrm{~mL} / \mathrm{min}$ and the split ratio was $58: 1$. The identification of the peaks of the samples was done with reference to a chromatographic profile containing FAME standards (Sigma Aldrich). Each sample was chromatographed twice and the percentage of fatty acid was calculated as the ratio of the partial area to the total area (Marikkar et al., 2010).

\section{Iodine value:}

All oil samples were analyzed for iodine value using the AOCS method Cd Id-92 (AOCS, 1999). 
Table 1. Fatty acid composition and iodine value data of coconut oil and coconut pairing oil samples

\begin{tabular}{|c|c|c|c|c|c|c|c|c|c|}
\hline \multirow{2}{*}{ Sample } & \multicolumn{9}{|c|}{ Variable } \\
\hline & Caprylic $\left(\mathbf{X}_{1}\right)$ & Capric $\left(\mathrm{X}_{2}\right)$ & Lauric $\left(\mathbf{X}_{3}\right)$ & Myristic $\left(\mathbf{X}_{4}\right)$ & Palmitic $\left(\mathbf{X}_{5}\right)$ & Stearic $\left(\mathbf{X}_{6}\right)$ & Oleic $\left(X_{7}\right)$ & Linoleic $\left(\mathbf{X}_{8}\right)$ & Iodine value $\left(X_{9}\right)$ \\
\hline CNO-1 & $5.69 \pm 0.01$ & $5.47 \pm 0.02$ & $48.04 \pm 0.02$ & $20.17 \pm 0.03$ & $9.00 \pm 0.01$ & $0.14 \pm 0.17$ & $8.47 \pm 0.05$ & $2.96 \pm 0.02$ & $8.29 \pm 0.16$ \\
\hline CNO-2 & $5.07 \pm 0.00$ & $5.34 \pm 0.00$ & $47.94 \pm 0.00$ & $20.54 \pm 0.00$ & $9.18 \pm 0.00$ & $0.05 \pm 0.00$ & $8.83 \pm 0.00$ & $2.89 \pm 0.00$ & $7.34 \pm 0.11$ \\
\hline CNO-3 & $5.06 \pm 0.06$ & $4.45 \pm 0.07$ & $48.47 \pm 0.18$ & $21.15 \pm 0.07$ & $9.08 \pm 0.04$ & $2.75 \pm 0.07$ & $6.57 \pm 0.40$ & $2.63 \pm 0.04$ & $4.75 \pm 0.78$ \\
\hline CNO-4 & $5.07 \pm 0.05$ & $5.53 \pm 0.28$ & $49.31 \pm 0.07$ & $20.48 \pm 0.04$ & $9.08 \pm 0.02$ & $1.01 \pm 0.01$ & $6.84 \pm 0.05$ & $2.71 \pm 0.28$ & $4.74 \pm 0.77$ \\
\hline CNO-5 & $4.82 \pm 0.27$ & $5.43 \pm 0.17$ & $48.55 \pm 0.54$ & $20.3 \pm 0.30$ & $9.235 \pm 0.16$ & $0.42 \pm 0.01$ & $8.23 \pm 0.55$ & $3.05 \pm 0.01$ & $7.47 \pm 1.24$ \\
\hline CPO-1 & $5.53 \pm 0.09$ & $3.87 \pm 0.04$ & $38.27 \pm 0.08$ & $20.59 \pm 0.28$ & $11.65 \pm 0.07$ & $0.02 \pm 0.01$ & $14.94 \pm 0.09$ & $2.22 \pm 0.16$ & $14.85 \pm 0.07$ \\
\hline CPO-2 & $6.00 \pm 0.07$ & $4.18 \pm 0.08$ & $39.37 \pm 0.08$ & $21.15 \pm 0.09$ & $11.61 \pm 0.08$ & $0.03 \pm 0.01$ & $15.19 \pm 0.10$ & $2.14 \pm 0.08$ & $14.94 \pm 0.08$ \\
\hline $\mathrm{CPO}-3$ & $3.23 \pm 0.08$ & $3.17 \pm 0.22$ & $36.78 \pm 0.08$ & $22.49 \pm 0.07$ & $13.32 \pm 0.04$ & $0.42 \pm 0.04$ & $17.88 \pm 0.09$ & $2.62 \pm 0.08$ & $17.46 \pm 0.06$ \\
\hline $\mathrm{CPO}-4$ & $2.7 \pm 0.02$ & $2.92 \pm 0.04$ & $35.84 \pm 0.11$ & $22.38 \pm 0.04$ & $13.89 \pm 0.05$ & $0.2 \pm 0.05$ & $19.07 \pm 0.09$ & $2.89 \pm 0.08$ & $18.27 \pm 1.56$ \\
\hline CPO-5 & $3.3 \pm 0.05$ & $3.6 \pm 0.12$ & $38.48 \pm 0.18$ & $21.63 \pm 0.06$ & $12.62 \pm 0.07$ & $1.23 \pm 0.15$ & $16.25 \pm 0.04$ & $2.92 \pm 0.05$ & $16.42 \pm 0.19$ \\
\hline
\end{tabular}

Each value in the table represents the mean \pm standard deviation of duplicate analyses. $\mathrm{CNO}$ refers to coconut oil and $\mathrm{CPO}$ refers to coconut pairing oil 
Figure 1. Score plot of PCA applied to fatty acid composition and iodine value data

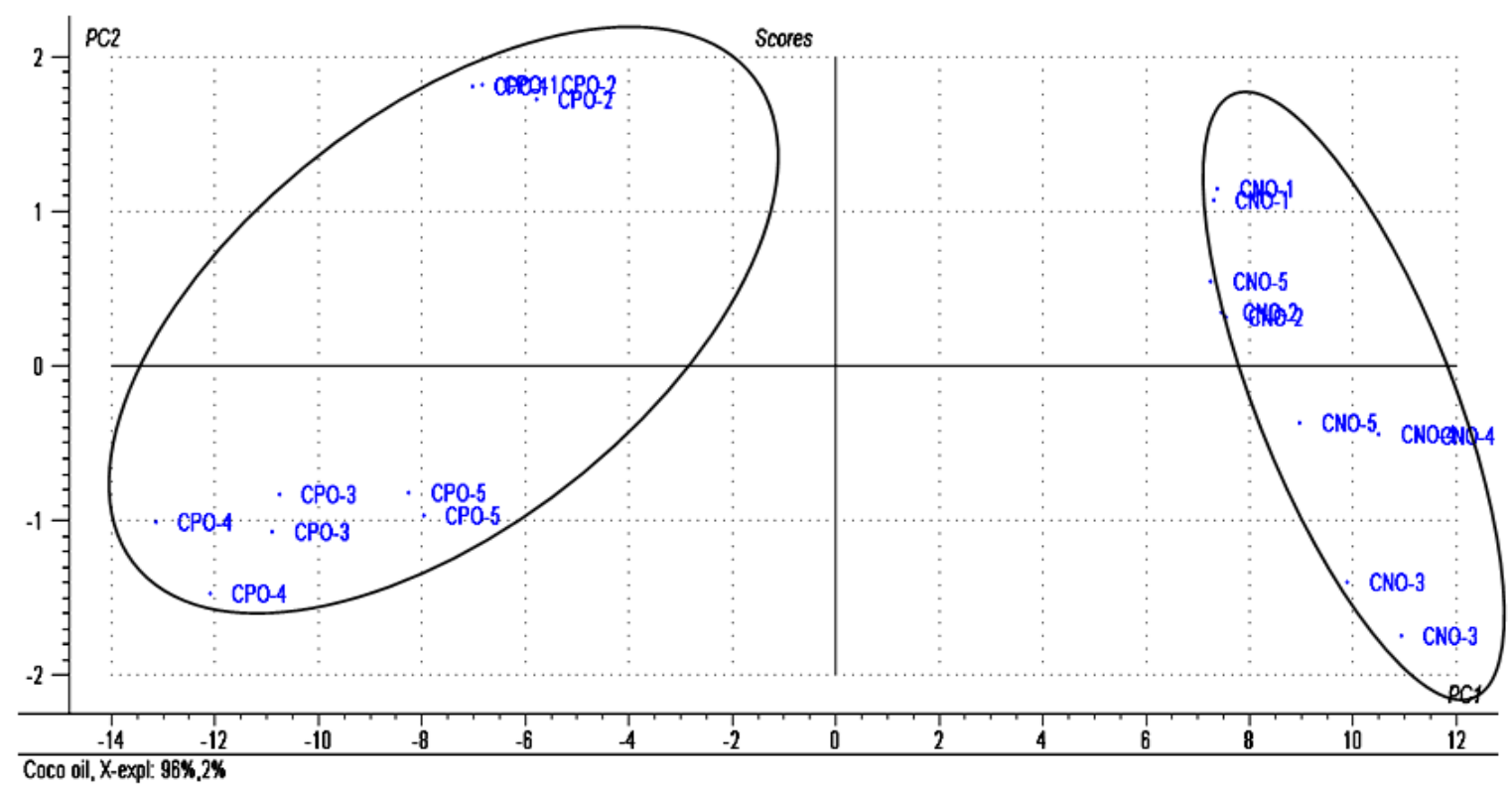

Figure 2. Loading plot of PCA applied to fatty acid composition and iodine value data

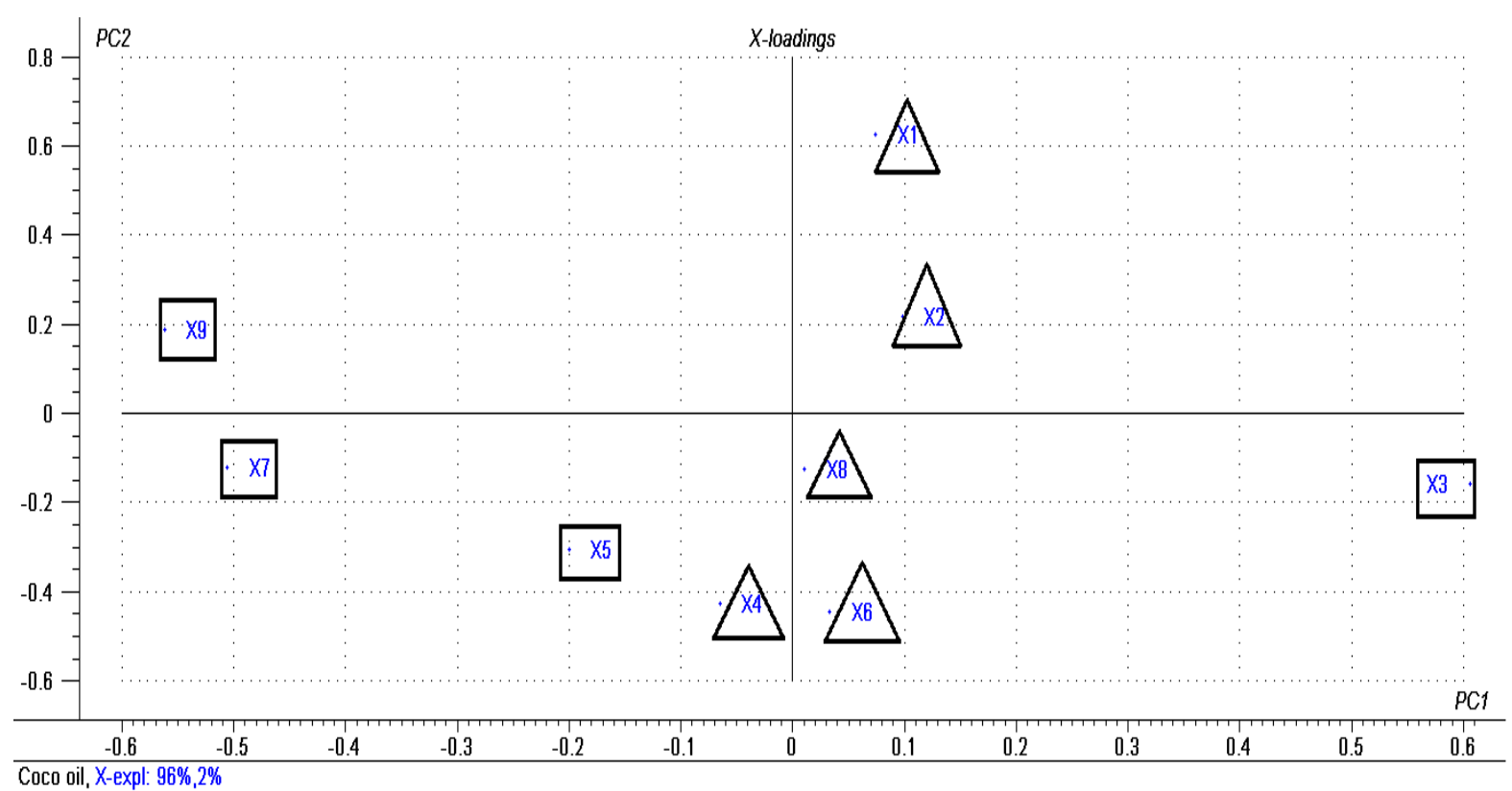




\section{Statistical analysis:}

Principal Component Analysis (PCA) for the grouping and classification models was carried out using Unscrambler 9.7 (Camo, USA) software.

\section{Results and Discussion}

GC analysis of FAME showed that all the $\mathrm{CNO}$ and CPO samples are found to possess caprylic $\left(X_{1}\right)$, capric $\left(X_{2}\right)$, lauric acid $\left(X_{3}\right)$, myristic $\left(X_{4}\right)$, palmitic $\left(X_{5}\right)$, stearic $\left(X_{6}\right)$ oleic $\left(X_{7}\right)$ and linoleic $\left(X_{8}\right)$ as the constituent fatty acids. As shown in Table 1, in both types of oils, lauric is the most dominant fatty acid while other fatty acids occur in variable amounts. This study assumes that these eight fatty acids $\left(X_{1}-X_{8}\right)$ along with the iodine value $\left(X_{9}\right)$ could be used as independent variables in PCA to distinguish CNO from CPO. The score plot shown in Figure 1 represent the projection of samples defined by principal component 1 (PC1) and principal component 2 (PC2). $\mathrm{PC} 1$ is the linear combination of variables that explain the highest variation among the samples, while PC2 is orthogonal to $\mathrm{PC} 1$ and exhibited the second largest variation. According to the Figure 1, PC1 describes $96 \%$ of the variance while PC2 explained $2 \%$ variance making up $98 \%$ variance. Analysis of the score plot (Figure 1) showed a clear separation between CNO and CPO samples in the PC1 component. While samples of $\mathrm{CNO}$ are located in positive side of $\mathrm{PC1}$, samples of $\mathrm{CPO}$ are located in negative side of $\mathrm{PC} 1$. Analysis of loading plot (Figure 2) indicates the variables, which give high influence on the separation of the samples in the score plot. Generally, variables that are located further away from the origin contribute the most variation to the principal component model. According to loading plot in Figure 2, $X_{3}$ (lauric), $X_{7}$ (oleic) and $X_{9}$ (iodine value) are the most discriminating variables on the separation of the two types of oil samples in the PC1 component. While variables $X_{7}$ (oleic) and $X_{9}$ (iodine value) exhibited negative loadings, $X_{3}$ (lauric) had positive loadings. Along PC2 axis $\mathrm{CNO}-1$ and $\mathrm{CNO}-2$ are separated from CNO-3, CNO-4 and CNO-5. Likewise, CPO-1 and CPO-2 are separated from CPO-3, CPO-4 and CPO-5 along PC2 axis.
According to the loading plot in Figure 2, $X_{1}$ (caprylic), $X_{4}$ (myrictic) and $X_{6}$ (stearic) are the variables that contribute the highest variation observed in PC2. While $X_{I}$ (caprylic) exhibited highest positive loading in PC2 axis, $X_{4}$ (myrictic) and $X_{6}$ (stearic) exhibited highest negative loading in PC2 axis. Hence, the applications of PCA to the fatty acid compositional and iodine value data greatly help to the discrimination of coconut oil from the coconut pairing oil samples.

\section{Conclusions}

This study demonstrated that iodine value, lauric and oleic acid contents are the most sensitive parameters to distinguish coconut oil from coconut pairing oil. The PCA model developed in this study could become a useful reference for future classification of these two oils. Hence, it could help to control adulteration practices taking place in the coconut oil industry.

\section{Reference}

AOCS, 1999. Official methods and recommended practices of the American Oil Chemists' Society. $5^{\text {th }}$ ed., American Oil Chemists' Society Champaign, IL, USA.

PORIM Test Methods. 1995. Palm Oil Research Institute of Malaysia, Kuala Lumpur. pp 83-91.

Marikkar, J.M.N. and Madhrapperume, W.S. 2011. Coconut. In: Tropical and subtropical food processing and packaging, Siddiq M (Ed.) John-Wiley Publishing Co. Ames., Iowa, USA (In press).

Marikkar, J.M.N., Ng, S.L. and Long, K. 2010. Composition and thermal analysis of lipids from pre-fried chicken nuggets, J. Am. Oil Chem. Soc. 88: 749-754.

Nathanael, W.R.N. 1966. Moisture and other quality factors of copra, Ceyl. Cocon. Quart. 17: 1-41. 